\title{
Total Cyanide Mass Measurement with Micro Ion-Selective Electrode for Determination of Specific Activity of Carbon-11 Cyanide
}

\author{
Colleen Shea ${ }^{\dagger}$, David L. Alexoff ${ }^{\dagger *}$, Dohyun Kim ${ }^{\dagger}$, Ruma Hoque ${ }^{\dagger}$, Michael J. Schueller ${ }^{\dagger}$, \\ Joanna S. Fowler ${ }^{\dagger}$, Wenchao $\mathrm{Qu}^{{ }^{* *}}$ \\ ${ }^{\dagger}$ Biological, Environmental and Climate Sciences Department, Brookhaven National Laboratory, \\ Upton, NY 11973, USA
}

\begin{abstract}
In this research, we aim to directly measure the specific activity (SA) of the carbon-11 cyanide $\left(\left[{ }^{11} \mathrm{C}\right] \mathrm{CN}^{-}\right)$produced by our in-house built automated $\left[{ }^{11} \mathrm{C}\right] \mathrm{HCN}$ production system and to identify the major sources of ${ }^{12} \mathrm{C}$-cyanide $\left({ }^{12} \mathrm{CN}^{-}\right)$. The $\left[{ }^{11} \mathrm{C}\right] \mathrm{CN}^{-}$is produced from $\left[{ }^{11} \mathrm{C}\right] \mathrm{CO}_{2}$, which is generated by the ${ }^{14} \mathrm{~N}(\mathrm{p}, \alpha){ }^{11} \mathrm{C}$ nuclear reaction using a cyclotron. Direct measurement of cyanide concentrations was accomplished using a relatively inexpensive, and easy to use ion selective electrode (ISE) which offered an appropriate range of sensitivity for detecting mass. Multiple components of the $\left[{ }^{11} \mathrm{C}\right] \mathrm{HCN}$ production system were isolated in order to determine their relative contributions to ${ }^{12} \mathrm{CN}^{-}$mass. It was determined that the system gases were responsible for approximately $30 \%$ of the mass, and that the molecular sieve/nickel furnace unit contributed approximately $70 \%$ of the mass. Beam on target ( $33 \mu \mathrm{A}$ for 1 and $10 \mathrm{~min}$ ) did not contribute significantly to the mass. Additionally, we compared the SA of our $\left[{ }^{11} \mathrm{C}\right] \mathrm{HCN}$ precursor determined using the ISE to the SA of our current $\left[{ }^{11} \mathrm{C}_{\mathrm{CN}^{-}}\right.$derived radiotracers determined by HPLC to assure there was no significant difference between the two methods.
\end{abstract}


These results are the first reported use of an ion selective electrode to determine the SA of nocarrier-added cyanide ion, and clearly show that it is a valuable, inexpensive and readily available tool suitable for this purpose.

\section{Key Words:}

Carbon-11 Cyanide, Automated $\left[{ }^{11} \mathrm{C}\right] \mathrm{HCN}$ Production System, Micro Ion Selective Electrode, Specific Activity 


\section{Corresponding Author:}

Qu, Wenchao

Brookhaven National Laboratory, Biological, Environmental and Climate Sciences Department, Building 555, Upton, NY 11973

Phone (O): (631)344-4221

E-mail: wqu@bnl.gov

\section{Co-corresponding Author:}

Alexoff, David L.

Brookhaven National Laboratory, Biological, Environmental and Climate Sciences Department, Building 555, Upton, NY 11973

Phone (O): (631)344-4221

E-mail: alexoff@,bnl.gov

\section{Authors:}

Shea, Colleen

Brookhaven National Laboratory, Biological, Environmental and Climate Sciences Department, Building 901, Upton, NY 11973, USA

Phone (O): (631)344-4558

E-mail: cshea@,bnl.gov

Kim, Dohyun

Brookhaven National Laboratory, Biological, Environmental and Climate Sciences Department, Building 555, Upton, NY 11973, USA

Phone (O): 631-344-4393

E-mail: dohkim@bnl.gov

Hoque, Ruma

Brookhaven National Laboratory, Biological, Environmental and Climate Sciences Department, Building 901, Upton, NY 11973, USA

Phone (O) (631)344-4563

Email: hoqueruma@gmail.com

Schueller, J. Michael

Brookhaven National Laboratory, Biological, Environmental and Climate Sciences Department, Building 901, Upton, NY 11973, USA

Phone (O) (631)344-5044

E-mail: mschueller@bnl.gov

Fowler, S. Joanna

Brookhaven National Laboratory, Biological, Environmental and Climate Sciences Department, Building 555, Upton, NY 11973, USA

Phone (O): 631-344-4365

E-mail: fowler@,bnl.gov 


\section{Introduction}

The gas phase production of no-carrier-added (NCA) carbon-11 labeled $\mathrm{HCN}$ $\left(\left[{ }^{11} \mathrm{C}\right] \mathrm{HCN}\right)$ in sufficient quantities for radiotracer synthesis was first described in 1973 (Christman et al. 1973; Christman et al. 1975) and carbon-11 cyanide $\left(\left[{ }^{11} \mathrm{C}\right] \mathrm{CN}{ }^{-}\right)$is now a common precursor used in the radiosynthesis of radiotracers for Positron Emission Tomography (PET) imaging studies of various biological systems (Antoni et al. 2003; Ferrieri 2003). Many PET imaging agents, including amino acids, primary amines, nitriles, sugars, amides and carboxylic acids have been synthesized starting from $\left[{ }^{11} \mathrm{C}\right] \mathrm{CN}^{-}$(Antoni et al. 2003; Ermert and Coenen 2013) (Miller et al. 2008). As with most radiotracers, specific activity (SA, defined as the ratio of carbon-11 $\left({ }^{11} \mathrm{C}\right)$ radioactivity to carbon-12 $\left({ }^{12} \mathrm{C}\right)$ mass, and typically presented in units of $\mathrm{GBq} / \mu \mathrm{mol}$, or $\mathrm{Ci} / \mu \mathrm{mol}$ ), is a major concern (Lapi and Welch 2013). Despite being defined as NCA, implying an absence of intentionally added carbon-12 carbon dioxide $\left({ }^{12} \mathrm{CO}_{2}\right)$ in the $\left[{ }^{11} \mathrm{C}\right] \mathrm{CN}^{-}$production pathway, it is virtually impossible to eliminate all ambient ${ }^{12} \mathrm{CO}_{2}$ from the atmosphere and other sources such as gas streams and solid components of the cyanide production system. Based upon the reaction scheme of the cyanide production system (Scheme 1), the only forms of carbon which should impact the final mass are ${ }^{12} \mathrm{CO}_{2},{ }^{12} \mathrm{CH}_{4}$ (and potentially other alkanes) and ${ }^{12} \mathrm{CN}^{-}$itself. All of these could have a significant impact on reducing SA, but the one most likely to be present is ${ }^{12} \mathrm{CO}_{2}$. Atmospheric ${ }^{12} \mathrm{CO}_{2}$ is present at a level of $400 \mathrm{ppm}$, so even small system leaks or adsorption can have a detrimental effect on the total mass of the final product (Jones 2013).

In an effort to maximize the SA of $\left[{ }^{11} \mathrm{C}\right] \mathrm{HCN}$ produced using our in-house built automated $\left[{ }^{11} \mathrm{C}\right] \mathrm{HCN}$ production system, we attempted to determine the mass contributions of all potential ${ }^{12} \mathrm{CO}_{2}$ and other stable carbon sources in the $\left[{ }^{11} \mathrm{C}\right] \mathrm{HCN}$ production pathway, and to 
ultimately utilize this data to modify the system and/or its components to improve the SA. For evaluating the SA of $\left[{ }^{11} \mathrm{C}\right] \mathrm{HCN}$, one possible method is to convert $\left[{ }^{11} \mathrm{C}\right] \mathrm{CN}-$ to specific radioactive products, whose SA can easily be measured by a simple analytical radio-HPLC method, and use that SA value as a surrogate for SA of $\left[{ }^{11} \mathrm{C}\right] \mathrm{HCN}$. Although one could argue that this indirect method should provide an accurate measurement, subsequent chemical steps, potential contamination of the starting material with trace product, and inadequate purification of the final radiotracer during such conversion process, could all potentially result in a lower SA for the radiotracer compared to its precursor, $\left[{ }^{11} \mathrm{C}\right] \mathrm{HCN}$. Thus, it is preferred to have a method to determine the SA of $\left[{ }^{11} \mathrm{C}\right] \mathrm{HCN}$ itself, independent of further processing. To the best of our knowledge, four different methods had been reported in 1980's (the early development stage of $\left[{ }^{11} \mathrm{C}\right] \mathrm{HCN}$ precursor) for directly measuring ${ }^{12} \mathrm{CN}^{-}$mass and SA: differential pulse polarography, gas chromatography, a proprietary photometric method from Merck, as well as a pyridine-pyrazolone spectrophotometric method of Epstein (Ding et al. 1989; Fowler et al. 1982; Meyer et al. 1990; Niisawa et al. 1984).

Unlike the most commonly used carbon-11 labeled radioprecursor, methyl iodide ([ $\left.\left[{ }^{11} \mathrm{C}\right] \mathrm{CH}_{3} \mathrm{I}\right)$ (Miller et al. 2008), which has a UV chromophore that lends itself to simple HPLC mass determination (Gomez-Vallejo and Llop 2008), there is no single widely accepted method to determine ${ }^{12} \mathrm{CN}^{-}$mass. There are numerous accepted methods for measuring ${ }^{12} \mathrm{CN}^{-}$ concentrations in aqueous solutions with limits of detection (LOD) ranging from 0.5 to 100 parts per billion (ppb). These include wet methods such as titration with silver nitrate (LOD $100 \mathrm{ppb})$ through to instrumental methods such atomic absorption (LOD 4.8 ppb) (Anon 2013; Ma and Dasgupta 2010). For this research, we chose to use an ion selective electrode (ISE) (LOD $50 \mathrm{ppb)}$ based upon several advantages of this method: availability, ease of use, and suitability to 
repeated measurements of over a period of several weeks. Specifically, we used a micro ISE that requires a small volume of sample for all experiments because this allowed a better simulation of our $\left[{ }^{11} \mathrm{C}\right] \mathrm{HCN}$ production and subsequent radiotracer synthesis process, in which only $0.2-1$ $\mathrm{mL}$ of solvent is generally used. The expected ${ }^{12} \mathrm{CN}^{-}$mass for all samples generated in this project was in the range of parts per million (ppm), so the sensitivity of this method was expected to be adequate for the study.

Herein we describe the results of this study which show the effects on mass resulting from isolating and eliminating multiple components of our automated $\left[{ }^{11} \mathrm{C}\right] \mathrm{HCN}$ production system, as well as specific activity measurements made on this system using the ISE to determine the mass values. The values obtained were then compared to recent SA determinations of two $\left[{ }^{11} \mathrm{C}\right] \mathrm{HCN}$ based radiotracers: $\left[{ }^{11} \mathrm{C}\right]$ Indole-3-acetic acid $\left(\left[{ }^{11} \mathrm{C}\right] \mathrm{IAA}\right)$ and L$\left[5-{ }^{11} \mathrm{C}\right]$-glutamine $\left(\mathrm{L}-\left[{ }^{11} \mathrm{C}\right] \mathrm{Gln}\right)$.

\section{Instruments, materials and methods}

\subsection{Apparatus and instruments}

The carbon-11 target used to produce the $\left[{ }^{11} \mathrm{C}\right] \mathrm{CO}_{2}$ for this study is an $18 \mathrm{~mL}$ internal volume 6061 aluminum body, wire-EDM cut, stepped conical target with an aluminum (5052) front foil supported by a water cooled grid. The target gas is an $\mathrm{O}_{2}$ diluted $\mathrm{N}_{2}$ gas $(300-500$ ppm $\mathrm{O}_{2}$ in $\mathrm{N}_{2}$ prepared by proportionally mixing an $\mathrm{O}_{2}$ doped $\mathrm{N}_{2}$ gas $\left(2 \% \mathrm{O}_{2}\right.$ in $\mathrm{N}_{2}$, grade 6.0$)$ with pure $\mathrm{N}_{2}$ (grade 5.0) and passing through a $\mathrm{CO}_{2}$ scrubber (Grace/Alltech PN 8119) to remove 
trace amount of ${ }^{12} \mathrm{CO}_{2}$. After loading the target to $360-400$ psi, it was bombarded with $33 \mu \mathrm{A}$ of $18 \mathrm{MeV}$ protons from a compact cyclotron (TR-19/9, EBCO) to produce $\left[{ }^{11} \mathrm{C}^{-} \mathrm{CO}_{2}\right.$.

The in-house built $\left[{ }^{11} \mathrm{C}\right] \mathrm{HCN}$ production system utilized in this research is a streamlined adaption of the original $\left[{ }^{11} \mathrm{C}\right] \mathrm{HCN}$ production system (Christman et al. 1973; Christman et al. 1975) (Iwata et al. 1987), which is fully automated and conveniently operated via a computer software interface with minimal user intervention (Scheme 2) (Kim et al. 2013). This system's major components are a molecular sieve/nickel (MS/Ni) furnace to trap $\left[{ }^{11} \mathrm{C}^{\mathrm{C}} \mathrm{CO}_{2}\right.$ (while also scrubbing $\mathrm{O}_{2}$ from the target) and later reduce $\left[{ }^{11} \mathrm{C}\right] \mathrm{CO}_{2}$ to $\left[{ }^{11} \mathrm{C}\right]$ methane $\left(\left[{ }^{11} \mathrm{C}\right] \mathrm{CH}_{4}\right)$, a mixer for mixing $\left[{ }^{11} \mathrm{C}_{\mathrm{CH}_{4}}\right.$ and ammonia gas, and a platinum $(\mathrm{Pt})$ furnace to convert $\left[{ }^{11} \mathrm{C}_{\mathrm{CH}}\right.$ to $\left[{ }^{11} \mathrm{C}\right] \mathrm{HCN}$. Helium gas is used to transfer ${ }^{11} \mathrm{C}$ radioactivity from one module of the system to the next. After direct unloading of $\left[{ }^{11} \mathrm{C}\right] \mathrm{CO}_{2}$ from the cyclotron target to the $\left[{ }^{11} \mathrm{C}\right] \mathrm{HCN}$ production box, followed by $10 \mathrm{~min}$ of processing, the desired $\left[{ }^{11} \mathrm{C}\right] \mathrm{HCN}$ product was directly delivered using primarily ammonia gas into a reaction vessel that was pre-installed in a hot cell. The hydrogen $\left(\mathrm{H}_{2}\right.$, grade 6.0, $>99.9999 \%$, Praxair) and helium (He, grade 5, ultra high purity, Praxair) gases were all pre-purified by passing through a scrubber (All-Pure Purifier, Alltech) before being introduced to the production system. The ammonia $\left(\mathrm{NH}_{3}\right.$, grade 4.5 , Praxair) used in this system was directly released from the tank and passed through a $\mathrm{KOH}$ pellet loaded drying tube before introducing to the $\left[{ }^{11} \mathrm{C}\right] \mathrm{HCN}$ production box. When the MS/Ni furnace packing material needed replacing, the following procedure was performed for pre-activation: the furnace was heated to $420^{\circ} \mathrm{C}$ with $\mathrm{He}$ flow for $30 \mathrm{~min}$ or until no water vapor was observed, after which the flow gas was switched to $\mathrm{H}_{2}$ for $30 \mathrm{~min}$. Once the reduction process was done, the furnace was cooled to $\leq 30^{\circ} \mathrm{C}$ under $\mathrm{H}_{2}$ flow. 
The ion selective electrode system (ISE) used to measure the ${ }^{12} \mathrm{CN}^{-}$mass consisted of a Lazar micro CN electrode (ISM-146CN) and a separate micro reference electrode (DJM-146) connected to a Jenco $6230 \mathrm{~N}$ mVMeter. Both electrodes used $10 \% \mathrm{w} / \mathrm{v}$ potassium nitrate fill solutions. A slightly modified method ((EPA) December, 1996) was used for preparing standards and making sample measurements. All samples were equilibrated in a $30 \pm 0.1^{\circ} \mathrm{C}$ water bath to compensate for fluctuations in ambient lab temperature. The footprint of the combined electrodes $(\sim 1 \mathrm{~cm})$ allowed measurement of sample volumes as low as $1 \mathrm{~mL}$, which permitted the simulation of normal $\left[{ }^{11} \mathrm{C}\right] \mathrm{CN}^{-}$radiolabeling reaction conditions.

For one experiment a dedicated small-animal PET camera (MicroPET R4, Siemens) was used to image the MS/Ni trap after target unloading. The MicroPET R4 is a first generation small-animal PET camera designed for imaging rodents and commonly used in pre-clinical research (Goertzen Andrew et al. 2012). The R4 has a physical opening of $12 \mathrm{~cm}$ and a resolution of $\sim 2 \mathrm{~mm}$ at the center of the imaging field of view of $10 \mathrm{~cm}$. It has an axial dimension of 7.8 $\mathrm{cm}$, which means a $7.8 \mathrm{~cm}$ length of the MS/Ni trap could be imaged completely. The MicroPET system includes a computer and software needed for data acquisition, image reconstruction and image analysis.

\subsection{Chemicals and standards}

Potassium cyanide (KCN, Sigma) used for preparing all standards was pre-dried in a 120 ${ }^{\circ} \mathrm{C}$ oven for two hours and stored in a desiccator. Potassium hydroxide (7.4 M, volumetric standard, Sigma) was used as an ionic strength adjustment (ISA) for all samples and standards. A KCN stock solution (100 ppm) was prepared monthly using deionized (D.I.) water and 1\% ISA and stored in the refrigerator when not in use. Multiple standards (KCN, $0.5-20 \mathrm{ppm})$ used 
for determining standard curve were prepared weekly by directly diluting the above KCN stock solution. Five-mL aliquots of each standard were removed for each use and basified with $1 \%$ ISA to maintain constant ionic strength. At least five standards were measured each day to determine the standard curve. The exact ranges of the standards used were determined by the expected concentration of the samples to be measured each day. A standard curve was generated each day before any samples were measured. A blank consisting of $1 \%$ ISA in D.I. water was measured with each curve. One or two standards close to or bracketing the samples were remeasured throughout the day. If the electrode drift was significant so that the standard no longer fell on or close to the plot (defined as $>10 \%$ change) obtained from morning measurement, all samples were re-measured and a new curve was generated for the later samples. Significant electrode shift (both slope and intercept) was sometimes observed during the course of the day; this was also observed by other researchers (Zlosnik and Williams 2004). The electrode was stored in a $0.3 \mathrm{ppm} \mathrm{KCN}$ standard solution both during the interval between sample measurements and overnight as recommended by the EPA method ((EPA) December, 1996).

\subsection{Experimental procedure}

$\left[{ }^{11} \mathrm{C}\right] \mathrm{KCN} / \mathrm{K}^{12} \mathrm{CN}$ samples preparation and measurement: to a sealed conical vial was added $0.75 \mathrm{~mL} \mathrm{KOH} / \mathrm{MeOH}$ solution $\left(0.1 \mathrm{M}\right.$, Fluka). Once the $\left[{ }^{11} \mathrm{C}\right] \mathrm{HCN} / \mathrm{H}^{12} \mathrm{CN}$ production process began, the output gas stream was bubbled through this solution at room temperature. After trapping was complete $(3 \mathrm{~min})$, the sample was heated in a $90^{\circ} \mathrm{C}$ oil bath under a gentle nitrogen gas stream to remove solvent $\mathrm{MeOH}$ and trace amounts of $\mathrm{NH}_{3}$ and then re-dissolved in $1 \mathrm{~mL}$ of D.I. water and vortexed for $10-15 \mathrm{sec}$. These test samples exactly mirrored the $\mathrm{KOH}$ concentration of the standards. Sample vials were immediately placed in a $30^{\circ} \mathrm{C}$ water bath for 5 min to equilibrate. Next, the electrodes were immersed into the sample and allowed to 
equilibrate another 5 min after which a millivolt $(\mathrm{mV})$ reading was taken. The sample vial was then swirled and a second $\mathrm{mV}$ reading was taken one min after the first reading to assure reproducibility. If the two readings differed by more than $2 \mathrm{mV}$, a third reading was taken shortly after the second. After each sample measurement, either one or two standards near or bracketing the sample value was re-measured to assure the electrode response had not drifted.

Preparation of a series of samples for $K^{12} \mathrm{CN}$ mass measurement:

Series 1: The system blank consisted of $0.75 \mathrm{~mL} 0.1 \mathrm{M} \mathrm{KOH}$ in $\mathrm{MeOH}$ dried to completeness and re-dissolved in $1 \mathrm{~mL}$ of water. Although the certificate of analysis (COA) stated there was no ${ }^{12} \mathrm{CN}^{-}$present, other ions can cause interference with the electrode response ((EPA) December, 1996). This test allowed quantification of any ${ }^{12} \mathrm{CN}^{-}$mass contribution from the $\mathrm{KOH}$, glassware and argon stream. Series 2: $\mathrm{NH}_{3}$ gas was trapped in the base to isolate the contribution of the ammonia alone. Series 3: The $\left[{ }^{11} \mathrm{C}\right] \mathrm{HCN}$ production box was re-plumbed so the He gas bypassed the MS/Ni furnace; this process allowed collection of a combined $\mathrm{NH}_{3}$ and He gas sample. Series 4: both the $\mathrm{H}_{2}$ gas and MS/Ni furnace were added back into the system, allowing normal operation of the box. Series 5: the cyclotron target was downloaded and fully processed through entire $\left[{ }^{11} \mathrm{C}\right] \mathrm{HCN}$ production system without cyclotron beam, i.e., without any radioactivity (Table 1). This sequence of tests enabled us to determine the cumulative contribution of various components of the automated $\left[{ }^{11} \mathrm{C}\right] \mathrm{HCN}$ production system on the ${ }^{12} \mathrm{CN}^{-}$ mass.

Radioactive samples SA determination:

Next, the target gas was bombarded for both 1 and $10 \mathrm{~min}$ and processed through the $\left[{ }^{11} \mathrm{C}\right] \mathrm{HCN}$ production box under normal operating conditions. The corresponding $\left[{ }^{11} \mathrm{C}\right] \mathrm{KCN}$ 
samples were collected and total mass of $\mathrm{K}^{12} \mathrm{CN}$ and $\mathrm{GBq}$ of $\left[{ }^{11} \mathrm{C}\right] \mathrm{HCN}$ were measured to determine the effect of bombardment time on both the mass of $\mathrm{K}^{12} \mathrm{CN}$ and the $\mathrm{SA}$ values of the samples. Additionally, the molecular sieve packing was reduced to one third of its original weight and the system was again tested with one min bombardments to determination of its contribution to the mass.

\section{Ni/MS trap Micro-PET imaging process:}

For the imaging experiment, the Ni/MS trap was removed from the automated system following a standard $33 \mu \mathrm{A} \cdot \mathrm{min}$ target irradiation and unloading and allowed to decay for $2-3 \mathrm{~h}$ until an appropriate imaging level was reached. The tube was sealed on both ends with parafilm and transported to the MicroPET imaging suite in a shielded box. The tube was positioned in the camera so that upstream portion of the tube was toward the bedside of the camera. The motorized bed was used to center the tube in the transaxial dimension. Because of the large axial field of view $(\sim 8 \mathrm{~cm}$ ), the entire MS/Ni packing (140mg of MS/200 $\mathrm{mg}$ of $\mathrm{Ni}$ ) spanning $\sim 50$ $\mathrm{mm}$ could be imaged. The PET scanner was configured using factory default parameters as described previously and data was acquired for 10 min (Alexoff et al. 2003). The raw data was histogrammed as a single frame and reconstructed using the filtered back projection algorithm using factor default settings. Corrections for scatter and attenuation were not applied to the sinogram data before image reconstruction. Detector normalization was carried out as recommended by the manufacturer. The results of this imaging experiment were used to estimate how much the Ni/MS packing could be reduced without sacrificing $\left[{ }^{11} \mathrm{C}^{-} \mathrm{CO}_{2}\right.$ trapping efficiency by evaluating the axial extent of the carbon-11 activity on the MS/Ni trap from the MicroPET image. 


\section{Results and discussion}

Our initial research started with the measurement of ${ }^{12} \mathrm{CN}^{-}$mass contributions from major components of the $\left[{ }^{11} \mathrm{C}\right] \mathrm{HCN}$ production system. The miniaturized $\left[{ }^{11} \mathrm{C}\right] \mathrm{HCN}$ production box in our laboratory is an in-house built, fully automated production system (Kim et al. 2013). The simplicity, reliability and high efficiency of this instrument has been demonstrated; it has already been operated successfully for hundreds of $\left[{ }^{11} \mathrm{C}\right] \mathrm{HCN}$ production cycles with radiochemical yields ranging from $40 \sim 70 \%$ (decay corrected). In addition, a series of carbon11 labeled PET radiotracers relying on this instrument have been developed in recent years (Figure 1) (Reid et al. 2011) (Best et al. 2012) (Qu et al. 2012) (Lee et al. 2013) (Qu et al. 2013) (Xu et al. 2014) (Wang et al. 2014) (Gleede et al. 2015). Before this research, the only reportable SA measurement for this instrument was based upon the SA measurements of the radiotracers that use $\left[{ }^{11} \mathrm{C}\right] \mathrm{HCN}$ as their radiolabeling precursor, which could distort our knowledge of the SA of the $\left[{ }^{11} \mathrm{C}\right] \mathrm{HCN}$ produced by this instrument. By directly measuring the amount of ${ }^{12} \mathrm{CN}^{-}$ generated from this instrument, we should have both a better understanding of the major sources of ${ }^{12} \mathrm{CN}^{-}$and an opportunity to further improve the SA of the radiotracers that use $\left[{ }^{11} \mathrm{C}\right] \mathrm{HCN}$ as a precursor.

Due of the engineering of this automated $\left[{ }^{11} \mathrm{C}\right] \mathrm{HCN}$ production box, it was not possible to isolate all components for evaluation without a major redesign. However, after scrutinizing entire $\left[{ }^{11} \mathrm{C}\right] \mathrm{HCN}$ production scheme we were able to isolate several components, which could be major sources of carbon, including the cyclotron target and target gas (1), $\mathrm{NH}_{3}$ gas stream (5), the $\mathrm{He}$ and $\mathrm{NH}_{3}$ combined gas stream (3 and 5), $\mathrm{H}_{2}$ gas stream (2) and MS/Ni furnace (4), as 
well as the effect of the beam on target (6) (Scheme 2). Our investigation began by evaluating the contribution of each of the above potential sources either separately or combined on the total mass of $\mathrm{K}^{12} \mathrm{CN}$. The results are listed in Table 1 and also bar-graphed in Figure 2 for a more direct comparison.

The results of the component testing of the system show that the contribution of the ammonia and helium gases is minimal (Table 1). The $\mathrm{NH}_{3}$ only generated $0.78 \pm 0.3 \mathrm{ppm}(\mathrm{n}=$ 10) of $\mathrm{K}^{12} \mathrm{CN}$ (Series 2) and the combination of $\mathrm{NH}_{3}$ and He provided $1.0 \pm 0.3 \mathrm{ppm}(\mathrm{n}=7)$ of $\mathrm{K}^{12} \mathrm{CN}$ (Series 3). Both of these were approximately $1-1.5$ fold higher than the blank samples (Series 1, 0.4 ppm of $\mathrm{K}^{12} \mathrm{CN}$ ). When $\mathrm{Ni} / \mathrm{MS}$ furnace component was added to the tested system, the total mass of $\mathrm{K}^{12} \mathrm{CN}$ was $4.6 \pm 0.99 \mathrm{ppm}(\mathrm{n}=10)$, jumping to 10.5 fold higher than blank samples (Series 4). The further addition of target gas, which is equivalent to normal operating conditions of the system (i.e., downloading the target gas from cyclotron into $\left[{ }^{11} \mathrm{C}\right] \mathrm{HCN}$ production box and conducting all operations except for the bombardment), increased the amount of $\mathrm{K}^{12} \mathrm{CN}$ an additional two fold (Series 5) and total mass of $\mathrm{K}^{12} \mathrm{CN}$ reached $5.4 \pm 1.9$ $\operatorname{ppm}(\mathrm{n}=13)$.

It is clear from above results that the combined contribution of $\mathrm{NH}_{3}$ and $\mathrm{He}$ to the total $\mathrm{K}^{12} \mathrm{CN}$ mass is $12 \%$. It is reasonable to speculate that switching to a higher grade of either or both gases may help to reduce the $\mathrm{K}^{12} \mathrm{CN}$ mass. The target gas and its delivery line system accounted for $15 \%$ of $\mathrm{K}^{12} \mathrm{CN}$ mass contribution. So, a target and delivery line cleaning process, such as pre-load and dumping the target gas once or several times before the production bombardment, should also help to modestly reduce the $\mathrm{K}^{12} \mathrm{CN}$ mass. However, the largest ${ }^{12} \mathrm{C}$ mass source came from Ni/MS furnace and $\mathrm{H}_{2}$ gas combined component and it contributed $73 \%$ of $\mathrm{K}^{12} \mathrm{CN}$ total mass. During each production cycle of $\left[{ }^{11} \mathrm{C}\right] \mathrm{HCN}$, the Ni/MS furnace has to be 
pre-conditioned to remove moisture and atmospheric air with following operations (Kim et al. 2013): 1). Heat $\mathrm{Ni} / \mathrm{MS}$ furnace at $420^{\circ} \mathrm{C}$ for $5 \mathrm{~min}$ under the flow of $\mathrm{H}_{2} ; 2$ ). Cool the furnace to room temperature with continuous flow of $\mathrm{H}_{2}$ for 10 min; 3). Remove $\mathrm{H}_{2}$ by purging the system with He for 2 min; 4). Switch off the inlet and outlet valves and the Ni/MS furnace is ready to collect $\left[{ }^{11} \mathrm{C}\right] \mathrm{CO}_{2}$ generated from the cyclotron. By reviewing these operations, we can speculate there are two possible reasons that the operation of Ni/MS furnace is the major source of carbon for the complete system: 1). There is still a trace amount of ${ }^{12} \mathrm{CO}_{2}$ absorbed on the molecular sieves even after above first step; 2). During the operations from step 2 to step 4, although the furnace is maintained with positive pressure, there is still an unavoidable trace amount of atmospheric air entering the furnace through connecting units and valves. This latter explanation provides a good correlation with the experimental results listed in Table 1. When comparing the above findings with a recent $\left[{ }^{11} \mathrm{C}\right] \mathrm{CH}_{3}$ I specific activity investigation report (Gomez-Vallejo and Llop 2008), it is very interesting to find that the factors impacting SA of carbon-11 radiolabeled tracers were highly dependent on the specific research site. In their report, the major contribution of carbon-12 came from the cyclotron target and bombardment process. In our investigation, $\mathrm{Ni} / \mathrm{MS}$ furnace operation process contributed majority of $\mathrm{K}^{12} \mathrm{CN}$ mass, while the cyclotron target and bombardment processes just had minimal contribution to $\mathrm{K}^{12} \mathrm{CN}$ mass.

After testing the complete $\left[{ }^{11} \mathrm{C}\right] \mathrm{HCN}$ production system and identifying the ${ }^{12} \mathrm{CN}^{-}$mass contribution from each component, the ISE method was next utilized to measure the SA of $\left[{ }^{11} \mathrm{C}\right] \mathrm{HCN}$ samples that were generated from $1 \mathrm{~min}$ and $10 \mathrm{~min}$ cyclotron beams. These times bracket the low and high end of typical beam times when we synthesize a $\left[{ }^{11} \mathrm{C}\right] \mathrm{HCN}$ based radiotracer in our laboratory. In addition, having identified the MS/Ni trap and/or its operation as the major source of carbon-12 from the results above (see Table 1), we hypothesized that it 
may be possible to increase the SA of $\left[{ }^{11} \mathrm{C}\right] \mathrm{HCN}$ by simply decreasing the amount of Ni/MS furnace packing materials. To assure that reducing the amount of packing materials in Ni/MS furnace would still be adequate to efficiently trap the $\left[{ }^{11} \mathrm{C}\right] \mathrm{CO}_{2}$ radioactivity, we first conducted an imaging experiment to understand the distribution of the trapped $\left[{ }^{11} \mathrm{C}\right] \mathrm{CO}_{2}$ on the $\mathrm{Ni} / \mathrm{MS}$ trapping/catalyst bed using our MicroPET scanner. The image obtained showed that the most $\left[{ }^{11} \mathrm{C}\right] \mathrm{CO}_{2}$ was trapped between $1 \mathrm{~mm}$ and $6 \mathrm{~mm}$ of the start of packing (Figure 3). The imaging results indicated that over half amount of nickel and molecular sieve mixture was unnecessary for trapping $\left[{ }^{11} \mathrm{C}_{\mathrm{CO}_{2}}\right.$. We then reduced total packing material in the Ni/MS furnace to $1 / 3$ of its original amount and measured the SA of $\left[{ }^{11} \mathrm{C}\right] \mathrm{HCN}$ samples that were generated from $1 \mathrm{~min}$ cyclotron beams.

For $1 \mathrm{~min}$ and $10 \mathrm{~min}$ cyclotron beams (normally producing $3.7 \pm 0.18 \mathrm{GBq}$ and $31.8 \pm$ 1.6 GBq $\left[{ }^{11} \mathrm{C}_{\mathrm{CO}}\right.$, respectively) we trapped $1.43 \pm 0.15 \mathrm{GBq}(\mathrm{n}=10)$ and $10.2 \pm 3.0 \mathrm{GBq}(\mathrm{n}=$ 3) $\left[{ }^{11} \mathrm{C}\right] \mathrm{HCN}$ radioactivity in the collecting vial, respectively. The specific activity was calculated back to end of bombardment (EOB) for direct comparison, and were $29.3 \pm 9.6$ $\mathrm{GBq} / \mu \mathrm{mol}$ and $277 \pm 29.6 \mathrm{GBq} / \mu \mathrm{mol}$ for each beam length (Figure 4). For the corresponding 1 min beam time experiments with reduced packing, we had $1.66 \pm 0.16 \mathrm{GBq}\left[{ }^{11} \mathrm{C}\right] \mathrm{HCN}$ radioactivity trapped in the collecting vial and the specific activity of samples was $15.5 \pm 2.8$ $\mathrm{GBq} / \mu \mathrm{mol}(\mathrm{EOB}, \mathrm{n}=7$ ) (Figure 4). Rather than increasing SA, the reduction of packing materials in the Ni/MS furnace had the opposite effect. These results added weight to our speculation that the major contribution of total $\mathrm{K}^{12} \mathrm{CN}$ mass from $\mathrm{Ni} / \mathrm{MS}$ furnace operation must be contamination from a trace amount of atmospheric air which entered into the system through connecting units and valves during system operations. Under such circumstances, the amount of packing materials is not the determining factor for total $\mathrm{K}^{12} \mathrm{CN}$ mass. Instead, identifying ways 
to diminish the contamination from atmospheric air during the $\left[{ }^{11} \mathrm{C}\right] \mathrm{HCN} / \mathrm{H}^{12} \mathrm{CN}$ production cycle is likely the most important factor for improving the SA of the $\left[{ }^{11} \mathrm{C}\right] \mathrm{HCN}$ precursor.

In recent years, we have repeatedly synthesized two important $\left[{ }^{11} \mathrm{C}\right] \mathrm{HCN}$ radioprecursor based PET tracers, $\left[{ }^{11} \mathrm{C}\right]$ indole-3-acetic acid $\left(\left[{ }^{11} \mathrm{C}\right] \mathrm{IAA}\right)$ and L- $\left[5-{ }^{11} \mathrm{C}\right]$-glutamine $\left(\mathrm{L}-\left[{ }^{11} \mathrm{C}\right] \mathrm{Gln}\right)$, to support our plant imaging research program (Scheme 3) (Reid et al. 2011) (Xu et al. 2014) (Lee et al. 2015) (Gleede et al. 2015). The SA of first radiotracer, $\left[{ }^{11} \mathrm{C}\right] \mathrm{IAA}$, was measured directly by analytical radio-HPLC with UV detection. During our most recent production cycle the product $\left[{ }^{11} \mathrm{C}\right]$ IAA SA was $47.4 \pm 12.5 \mathrm{GBq} / \mu \mathrm{mol}$ for a $2 \mathrm{~min}$ beam time $(\mathrm{n}=5)$ (Lee et al. 2015). These results are comparable with above $\left[{ }^{11} \mathrm{C}\right] \mathrm{HCN}$ SA results measured by the ISE method. The second tracer, L- $\left[{ }^{11} \mathrm{C}\right] \mathrm{Gln}$, had an average SA of $11.5 \pm 3.26 \mathrm{GBq} / \mu \mathrm{mol}$ with a 2 min beam time $(\mathrm{n}=15)$, which was lower than the SA results from above direct measurement of $\left[{ }^{11} \mathrm{C}\right] \mathrm{HCN}$ samples. Since the SA of L- $\left[{ }^{11} \mathrm{C}\right] \mathrm{Gln}$ was measured by an amino acid fluorenylmethyloxycarbonyl (Fmoc) derivatization method, it is possible that more error was induced than a direct mass measurement. Overall, these two sets of SA data seem to be in line with the SA results from $\left[{ }^{11} \mathrm{C}\right] \mathrm{HCN}$ sample ISE measurements.

\section{Conclusions}

In this study, we have demonstrated that an ISE method can be used to directly measure the ${ }^{12} \mathrm{CN}^{-}$mass of the samples collected from our in-house built automated $\left[{ }^{11} \mathrm{C}\right] \mathrm{HCN}$ production box. The analysis of samples obtained from testing isolated components of the $\left[{ }^{11} \mathrm{C}\right] \mathrm{HCN}$ production system provided us with a clear picture of the ${ }^{12} \mathrm{C}$ source: the major ${ }^{12} \mathrm{C}$ source came from the Ni/MS furnace operation process, which generated $\sim 70 \%$ amount of ${ }^{12} \mathrm{CN}^{-}$during the $\left[{ }^{11} \mathrm{C}\right] \mathrm{HCN}$ production cycle. The remainder of the ${ }^{12} \mathrm{CN}^{-}$mass came from three 
gas streams, $\mathrm{NH}_{3}$, He and target gas. The cyclotron bombardment process contributed a negligible amount of ${ }^{12} \mathrm{CN}^{-}$mass. In addition, we measured the SA of $\left[{ }^{11} \mathrm{C}\right] \mathrm{HCN}$ produced from this $\left[{ }^{11} \mathrm{C}\right] \mathrm{HCN}$ production box and compared the results with the SA measurements of two PET tracers recently produced in our laboratory. The SA results from two different methods were comparable and mutually confirmed the accuracy of both methods.

To further improve the SA of $\left[{ }^{11} \mathrm{C}\right] \mathrm{HCN}$ in the future, in addition to replacing current gases with higher grade equivalents, we need to focus on modifying the Ni/MS furnace to prevent/or decrease possible system contamination from atmospheric air during the operation of the $\left[{ }^{11} \mathrm{C}\right] \mathrm{HCN}$ production box. Modifications for preventing atmospheric air contamination in tubing, valves and junctions, as well as further investigation to determine the optimum volume and composition of packing materials in the Ni/MS catalysis bed, will all potentially help to improve the SA of all $\left[{ }^{11} \mathrm{C}\right] \mathrm{HCN}$ based PET radiotracers.

Finally, we hope this study will serve as a starting point for any facility that wishes to directly measure and maximize the specific activity of their $\left[{ }^{11} \mathrm{C}\right] \mathrm{HCN}$ production systems. It is clear that the ISE is a valuable, relatively simple and inexpensive analytical tool to measure NCA ${ }^{12} \mathrm{CN}^{-}$mass with an ideal detection range for this purpose. Although the major carbon-12 source may vary at each cyclotron facility, the method we established here could be easily adapted for tracing the major carbon-12 source(s), and results could help researchers to further improve the specific activity of their $\left[{ }^{11} \mathrm{C}\right] \mathrm{HCN}$ based PET radiotracers.

\section{Acknowledgement}


This manuscript has been co-authored by employees of Brookhaven Science Associates, LLC under Contract DE-AC02-98CH10886 with the U. S. Department of Energy, Office of Biological and Environmental Research within the Office of Science. Ruma Hoque was also supported by Science Undergraduate Laboratory Internships (SULI) program at the Office of Science, U. S. Department of Energy.

\section{References}

(EPA) USEPA (December, 1996) EPA Method 9213 - Potentiometric Determination of Cyanide in Aqueous Samples and Distillates with Ion-Selective Electrode. U.S. Environmental Protection Agency (EPA)

Alexoff DL et al. (2003) Reproducibility of 11C-raclopride binding in the rat brain measured with the MicroPET R4: effects of scatter correction and tracer specific activity Journal of Nuclear Medicine 44:815-822

Anon (2013) Handbook of Water Analysis, third edition edited by Leo M. L. Nollet and Leen S. P. De Gelder vol 105

Antoni G, Kihlberg T, Langstroem B (2003) Aspects on the synthesis of 11C-labeled compounds Handbook of Radiopharmaceuticals:141-194 doi:10.1002/0470846380.ch5

Best M, Gifford AN, Kim SW, Babst B, Piel M, Roesch F, Fowler JS (2012) Rapid radiosynthesis of [11C] and [14C]azelaic, suberic, and sebacic acids for in vivo mechanistic studies of systemic acquired resistance in plants Journal of Labelled Compounds and Radiopharmaceuticals 55:39-43 doi:10.1002/jlcr.1951

Christman DR, Finn RD, Karlstrom KI, Wolf AP (1973) Production of carrier-free hydrogen cyanide (carbon-11) for medical use and radiopharmaceutical syntheses. IX Journal of Nuclear Medicine 14:864-866

Christman DR, Finn RD, Karlstrom KI, Wolf AP (1975) Production of ultrahigh activity carbon-11-labeled hydrogen cyanide, carbon dioxide, carbon monoxide, and methane via the $14 \mathrm{~N}(\mathrm{p}, \alpha) 11 \mathrm{C}$ reaction. XV International Journal of Applied Radiation and Isotopes 26:435-442 doi:10.1016/0020-708x(75)90057-5

Ding YS, Antoni G, Fowler JS, Wolf AP, Langstrom B (1989) Synthesis of L-[5-11C]ornithine Journal of Labelled Compounds and Radiopharmaceuticals 27:1079-1090 doi:10.1002/jlcr.2580270913

Ermert J, Coenen HH (2013) Methods for 11C- and 18F-labeling of amino acids and derivatives for positron emission tomography imaging Journal of Labelled Compounds and Radiopharmaceuticals 56:225-236 doi:10.1002/jlcr.2996

Ferrieri RA (2003) Production and application of synthetic precursors labeled with carbon-11 and fluorine-18 Handbook of Radiopharmaceuticals:229-282 doi:10.1002/0470846380.ch7

Fowler JS, Arnett CD, Wolf AP, MacGregor RR, Norton EF, Findley AM (1982) [11C]Spiroperidol: synthesis, specific activity determination, and biodistribution in mice Journal of Nuclear Medicine 23:437-445 
Gleede T et al. (2015) Investigation of SN2 [11C]cyanation for base-sensitive substrates: an improved radiosynthesis of L-[5-11C]-glutamine Amino Acids 47:525-533 doi:10.1007/s00726-014-1883-z

Goertzen Andrew L et al. (2012) NEMA NU 4-2008 comparison of preclinical PET imaging systems Journal of nuclear medicine : official publication, Society of Nuclear Medicine 53:1300-1309

Gomez-Vallejo V, Llop J (2008) Specific activity of $11 \mathrm{CH} 3$ I synthesized by the "wet" method: Main sources of non-radioactive carbon Applied Radiation and Isotopes 67:111-114 doi:10.1016/j.apradiso.2008.09.012

Iwata R, Ido T, Takahashi T, Nakanishi H, lida S (1987) Optimization of [11C]HCN production and nocarrier-added [1-11C]amino acid synthesis Applied Radiation and Isotopes 38:97-102 doi:10.1016/0883-2889(87)90003-7

Jones N (2013) Troubling milestone for CO2 Nature Geoscience 6:589 doi:10.1038/ngeo1900

Kim D, Alexoff D, Kim SW, Hooker J, Ferrieri RA (2013) 11C-Labeled cyanide production system. Application: US Patent 2012-13584033; 20130045151

Lapi SE, Welch MJ (2013) A historical perspective on the specific activity of radiopharmaceuticals: What have we learned in the 35 years of the ISRC? Nuclear Medicine and Biology 40:314-320 doi:10.1016/j.nucmedbio.2012.12.010

Lee S, Alexoff DL, Shea C, Kim D, Schueller M, Fowler JS, Qu W (2015) Tetraethylene glycol promoted two-step, one-pot rapid synthesis of indole-3-[1-11C]acetic acid Tetrahedron Letters 56:517-520 doi:10.1016/j.tetlet.2014.12.014

Lee SJ et al. (2013) Rapid synthesis of C-11 labeled indole using [11C]cyanide Abstracts of Papers, 246th ACS National Meeting \& Exposition, Indianapolis, IN, United States, September 8-12, 2013:NUCL-64

Ma J, Dasgupta PK (2010) Recent developments in cyanide detection: A review Analytica Chimica Acta 673:117-125 doi:10.1016/j.aca.2010.05.042

Meyer GJ, Osterholz A, Harms T (1990) A systematic investigation of carbon-11 labeled hydrogen cyanide production Radiochimica Acta 50:43-47

Miller PW, Long NJ, Vilar R, Gee AD (2008) Synthesis of 11C, 18F, 150, and 13N radiolabels for positron emission tomography Angewandte Chemie, International Edition 47:8998-9033 doi:10.1002/anie.200800222

Niisawa K, Ogawa K, Saito J, Taki K, Karasawa T, Nozaki T (1984) Production of no-carrier-added 11Ccarbon disulfide and 11C-hydrogen cyanide by microwave discharge International Journal of Applied Radiation and Isotopes 35:29-33 doi:10.1016/0020-708x(84)90127-3

Qu W, Gleede T, Alexoff D, Schueller M, Fowler J (2013) Convenient radiosynthesis of carbon-11 labeled L-glutamine and L-asparagine for plant imaging Abstracts of Papers, 246th ACS National Meeting \& Exposition, Indianapolis, IN, United States, September 8-12, 2013:NUCL-39

Qu W et al. (2012) Preparation and characterization of L-[5-11C]-glutamine for metabolic imaging of tumors Journal of Nuclear Medicine 53:98-105 doi:10.2967/jnumed.111.093831

Reid AE et al. (2011) Radiosynthesis of C-11 labeled auxin (3-indolyl[1-11C]acetic acid) and its derivatives from gramine Journal of Labelled Compounds and Radiopharmaceuticals 54:433-437 doi:10.1002/jlcr.1894

Wang H, Lu Y, Liu L, Kim SW, Hooker JM, Fowler JS, Tonge PJ (2014) Radiosynthesis and biological evaluation of a novel enoyl-ACP reductase inhibitor for Staphylococcus aureus European Journal of Medicinal Chemistry 88:66-73 doi:10.1016/j.ejmech.2014.09.008

Xu Y et al. (2014) Radiosynthesis of 3-indolyl[1-11C]acetic acid for phyto-PET-imaging: An improved production procedure and formulation method Applied Radiation and Isotopes 91:155-160 doi:10.1016/j.apradiso.2014.05.017 
Zlosnik JEA, Williams HD (2004) Methods for assaying cyanide in bacterial culture supernatant Letters in Applied Microbiology 38:360-365 doi:10.1111/j.1472-765X.2004.01489.x 


\section{Tables}

Table 1. $\mathrm{K}^{12} \mathrm{CN}$ mass measurement results of five series of samples

\begin{tabular}{|c|c|c|c|c|}
\hline Series & Samples & $\begin{array}{c}\text { Included } \\
\text { components* }\end{array}$ & $\begin{array}{c}\text { PPM of } \mathrm{K}^{12} \mathrm{CN} \\
\text { (range) }\end{array}$ & $\begin{array}{c}\text { nmole of } \\
\mathrm{K}^{12} \mathrm{CN}\end{array}$ \\
\hline 1 & $\begin{array}{c}\mathrm{M} \mathrm{KOH} \text { in } \mathrm{MeOH} \\
(\text { blank, } n=2)\end{array}$ & $\mathrm{N} / \mathrm{A}$ & $0.4(0.1-0.7)$ & 6.0 \\
\hline 2 & $\mathrm{NH}_{3}$ only $(\mathrm{n}=10)$ & 5 & $\begin{array}{c}0.78 \pm 0.26(0.5 \\
-1.35)\end{array}$ & 12 \\
\hline 3 & $\begin{array}{c}\text { He (bypass Ni/MS) \& } \\
\mathrm{NH}_{3}(\mathrm{n}=7)\end{array}$ & 3,5 & $\begin{array}{c}1.0 \pm 0.3(0.72- \\
1.2)\end{array}$ & 15 \\
\hline 4 & $\begin{array}{c}\mathrm{He}, \mathrm{Ni} / \mathrm{MS}\left(\mathrm{H}_{2}\right) \& \mathrm{NH}_{3} \\
(\mathrm{n}=10)\end{array}$ & $2-5$ & $\begin{array}{c}4.6 \pm 0.99(3.5- \\
6.5)\end{array}$ & 71 \\
\hline 5 & Target $/$ no beam $(n=13)$ & $1-5$ & $\begin{array}{c}5.4 \pm 1.9(2.5- \\
8.7)\end{array}$ & 83 \\
\hline
\end{tabular}

*Component numbers reference Scheme 2. 


\section{Scheme Captions}

Scheme 1. Schematic of $\left[{ }^{11} \mathrm{C}\right] \mathrm{HCN}$ production process

Scheme 2. Schematic of $\left[{ }^{11} \mathrm{C}\right] \mathrm{HCN} / \mathrm{H}^{12} \mathrm{CN}$ production system and selected major ${ }^{12} \mathrm{CN}^{-}$mass generating components $\mathbf{1}-\mathbf{6}$

Scheme 3. Schematic of $\left[{ }^{11} \mathrm{C}\right] \mathrm{IAA}$ and L- $\left[{ }^{11} \mathrm{C}\right] \mathrm{Gln}$ radiosynthetic production process

\section{Figure Captions}

Figure 1. Carbon-11 labeled PET radiotracers recently developed in our laboratory using $\left[{ }^{11} \mathrm{C}\right] \mathrm{HCN}$ as a precursor

Figure 2. Amount of $\mathrm{K}^{12} \mathrm{CN}$ generated from different components or combined components in $\left[{ }^{11} \mathrm{C}\right] \mathrm{HCN}$ production system, error bars represent one standard deviation from the mean.

Figure 3. Composite figure from overlay of MicroPET image (carbon-11 activity) and scale drawing of experimental trapping tube (A quartz trapping tube (I.D.: $3 / 8$ inch $(6.99 \mathrm{~mm})$ ) was packed with $140 \mathrm{mg}$ of Ni catalyst and $200 \mathrm{mg}$ of molecular sieves.) Most of the activity is trapped between $1 \mathrm{~mm}$ and $6 \mathrm{~mm}$ of the start of packing.

Figure 4. The impact of beam length and molecular sieve volume on specific activity (corrected to EOB); error bars represent one standard deviation from the mean. 


\section{Scheme 1}

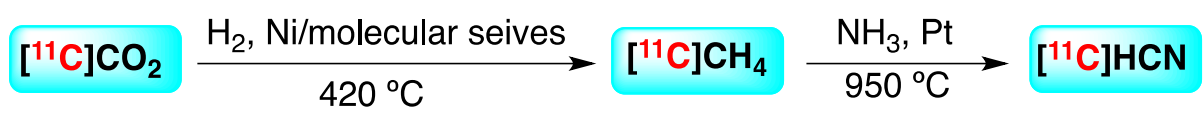

\section{Scheme 2}

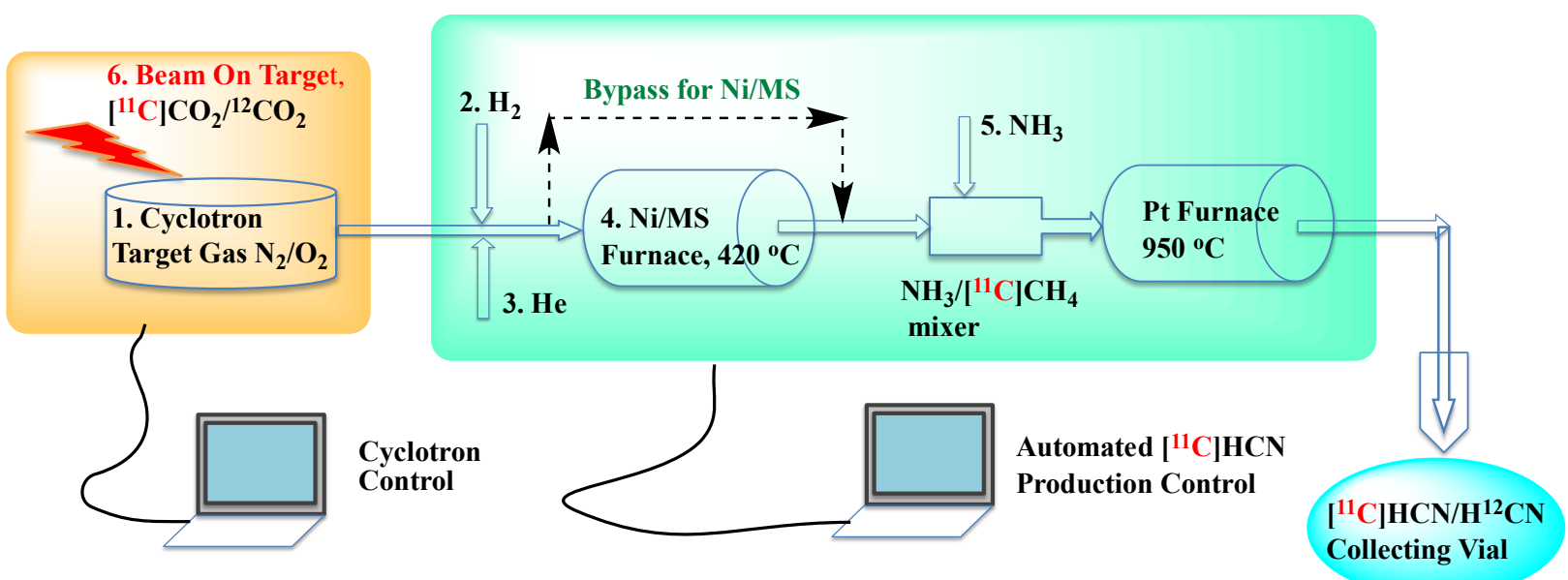

\section{Scheme 3}

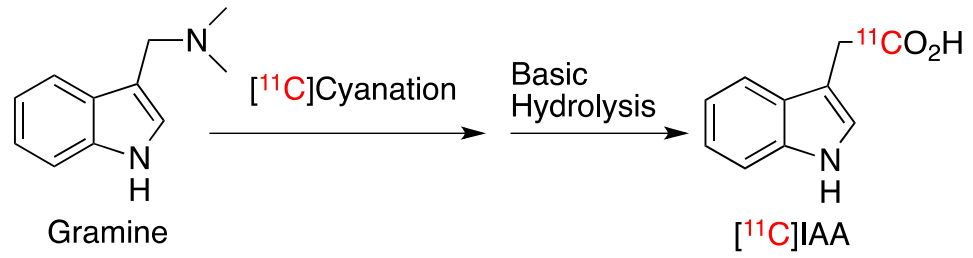

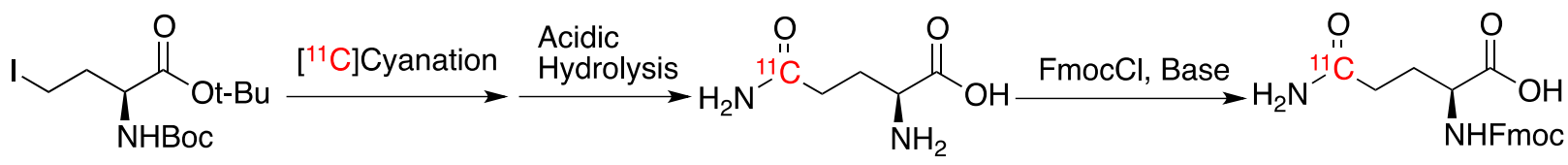
lodide precursor 
Figure 1<smiles>CC(C)(CCC(=O)O)CC(=O)O</smiles>

$\mathrm{n}=4:\left[{ }^{11} \mathrm{C}\right]$ Suberic acid $\mathrm{n}=5:\left[{ }^{11} \mathrm{C}\right]$ Azelaic acid $\mathrm{n}=6:\left[{ }^{11} \mathrm{C}\right]$ Sebacic acid<smiles>N#Cc1ccccc1Oc1ccc(C(F)(F)F)cc1O</smiles><smiles>N#Cc1c[nH]c2ccccc12</smiles>

$\left[{ }^{11} \mathrm{C}\right]$ Indole-3-acetonitrile ([11 C]IAN)<smiles>c1ccc2[nH]ccc2c1</smiles>

2-[11 C]Indole<smiles>O=C(O)Cc1c[nH]c2ccccc12</smiles>

$\left[{ }^{11} \mathrm{C}\right]$ Indole-3-acetic acid $\left(\left[{ }^{11} \mathrm{C}\right] \mathrm{IAA}\right)$<smiles>N[C@@H](CC[14C](N)=O)C(=O)O</smiles>

$\mathrm{L}-\left[5-{ }^{11} \mathrm{C}\right]-$ Glutamine (L-[ $\left.\left[{ }^{11} \mathrm{C}\right] \mathrm{GIn}\right)$<smiles>NC(=O)Cc1c[nH]c2ccccc12</smiles>

$\left[{ }^{11} \mathrm{C}\right]$ Indole-3-acetamide ([11 C]IAM)<smiles>N[C@H](C[14C](N)=O)C(=O)O</smiles>

L-[4-11 C]-Asparagine (L-[ $\left.{ }^{11} \mathrm{C}\right]$ Asn)

Figure 2

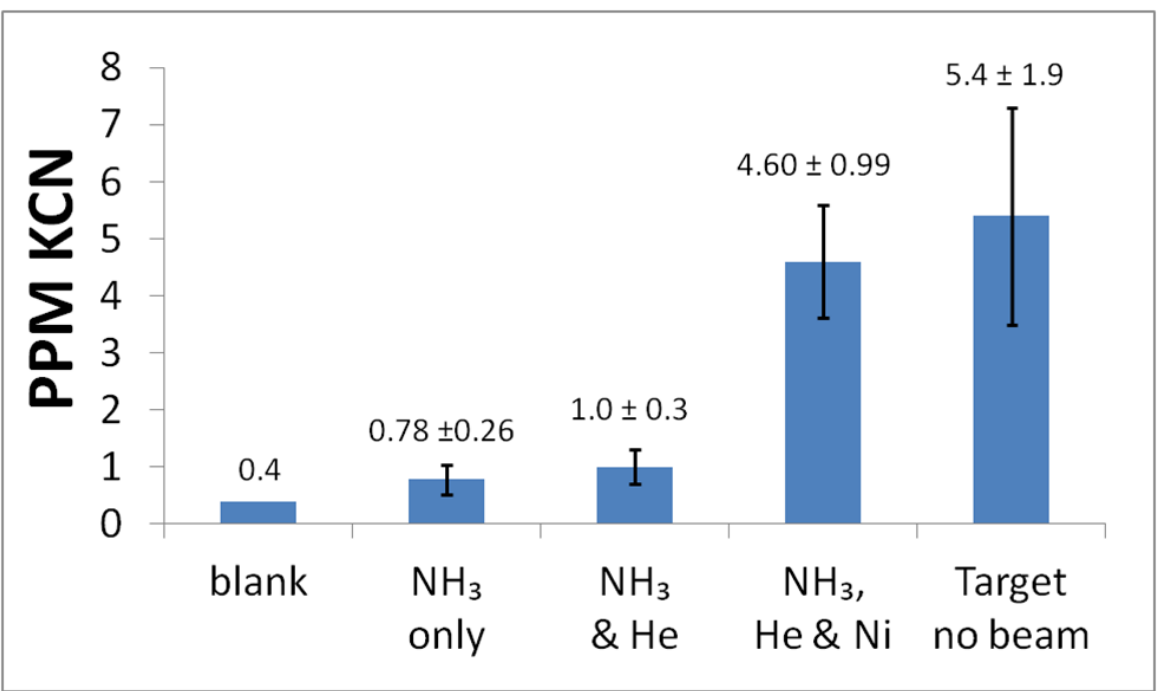


Figure 3

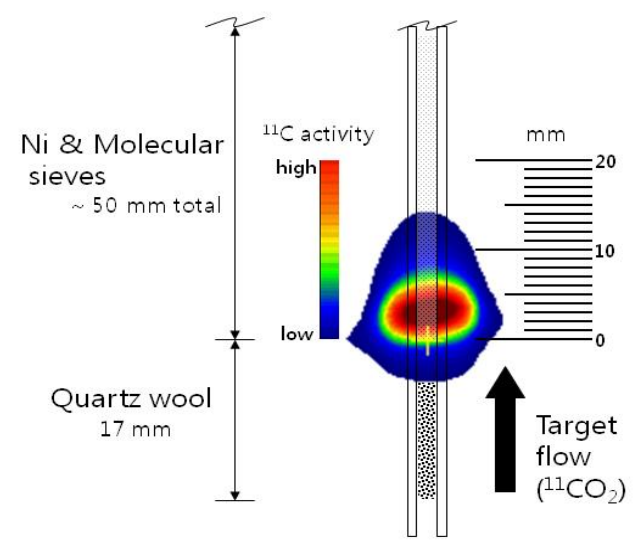

Figure 4

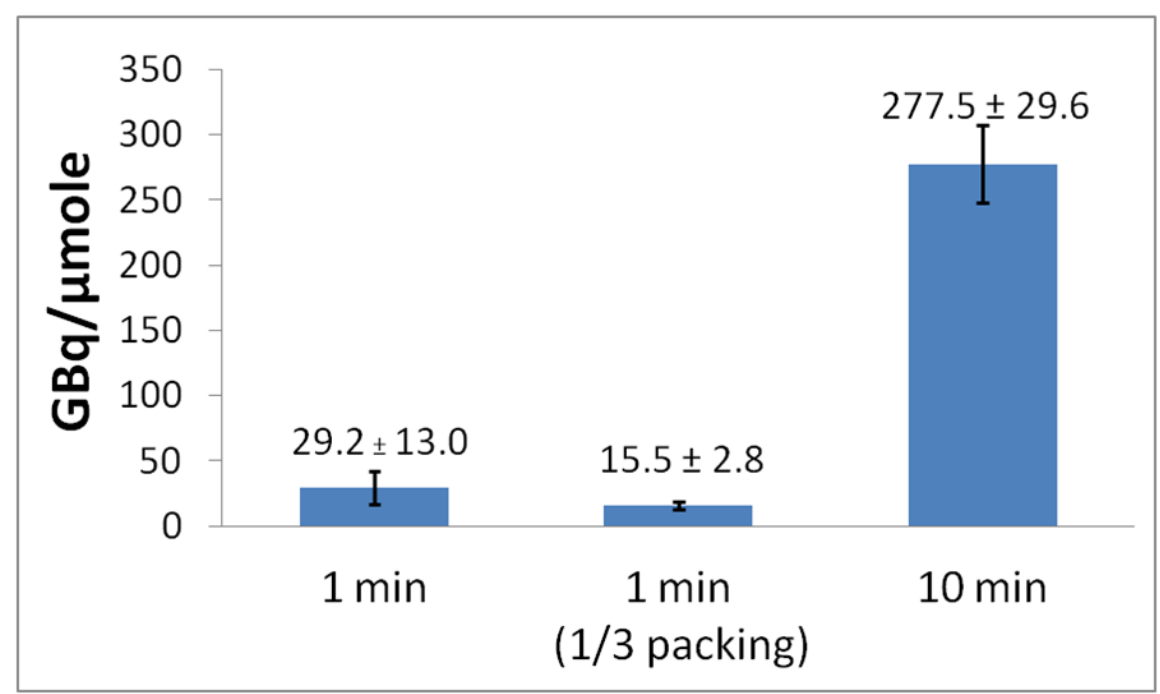

